\title{
COMO CONTOS DE FADAS E FANTASIA CONTRIBUEM NO DESENVOLVIMENTO PSÍQUICO E EMOCIONAL E NA INSERÇÃO DA CRIANÇA NO MUNDO LETRADO
}

\author{
Carolina Teles Fregonesi ${ }^{1}$, Thassia Souza Emídio ${ }^{2}$ \\ ${ }^{1}$ Discente do Curso de Psicologia da Faculdade de Ciências e Letras - UNESP, Campus de Assis. Aluna bolsista da \\ Fundação de Amparo à Pesquisa do Estado de São Paulo - FAPESP. ${ }^{2}$ Docente da Faculdade de Ciências e Letras - UNESP, \\ Campus de Assis. E-mail: carol teles14@hotmail.com.
}

\section{RESUMO}

Há muitos anos os contos de fadas têm sido fonte de estudo e reflexão para diversos autores. Esses resistem à passagem do tempo por abordarem sobre temas universais: como o amor e a luta entre o bem e o mal. Por tratarem de questões referentes às angustias e desejos humanos, podem contribuir para a compreensão do desenvolvimento emocional e psíquico. Assim, este trabalho visa refletir sobre como a noção de fantasia na obra de Freud se articula a acepção de que os contos contribuem para o desenvolvimento psíquico e emocional. Para tanto, foi realizado um estudo teórico, utilizando-se da Psicanálise enquanto fonte metodológica. Esperamos que esta pesquisa possa contribuir com as discussões sobre a teoria psicanalítica, a área da educação e com os estudos sobre o desenvolvimento infantil, como também estabelecer um diálogo entre o saber psicanalítico, as manifestações da cultura, uma vez que os contos são um importante legado cultural.

Palavras chave: contos de fadas, fantasia, psicanálise.

\section{INTRODUÇÃO E OBJETIVO}

Os contos de fadas foram criados há muito tempo e até hoje fazem parte do cotidiano dos seres humanos. Eles são desde a sua criação uma forma de fantasiar. Foram criados a partir de fantasias compartilhadas e do desejo humano de compreender seu mundo interno e o mundo a sua volta. Esses textos despertam fantasias que traduzem as necessidades, sonhos e medos dos seres humanos. Dessa forma, até os dias de hoje, são considerados um rico legado cultural, sendo fonte de estudo e reflexão para diversos autores.

Os contos não envelheceram com a passagem do tempo, pois ainda hoje apresentam em suas histórias assuntos relacionados às questões vividas pela sociedade contemporânea. Segundo Bettelheim (1977) e Corso e Corso (2006), no decorrer das histórias os contos tratam sobre questões universais e cotidianas como: disputas fraternas, desejos de amor e vingança, momentos de dificuldade e superação, dentre outros. Os contos de fadas apresentam uma linguagem simbólica, ou seja, a mesma linguagem do inconsciente. Assim possibilitando que o leitor entre em contato com seus medos e desejos, se identifique com os personagens e com isso possa pensar em suas questões internas e encontrar soluções simbólicas para essas. Dessa forma, pode-se dizer 
que os contos de fadas são regidos pelos mesmos processos do funcionamento psíquico. O que nos permite pensar também que esses textos despertam a capacidade de fantasiar em seus leitores, sendo a arte de sonhar e fantasiar necessária para o desenvolvimento psíquico e emocional e também para o processo de aprendizagem.

Going (1977) e Radino (2003) colocam que além de terem significados psicológicos, os contos de fadas, apresentam qualidades literárias. A linguagem simbólica, presente nos contos de fadas, é necessária para a inserção da criança no mundo letrado. Ela auxilia na construção do imaginário, na ativação da memória e da atenção, na aquisição de vocabulário, na construção do pensamento conceitual, na compreensão e assimilação da realidade, além de proporcionar momentos de prazer e autoconhecimento no qual o leitor dá um sentido pessoal à história contada.

Esta pesquisa tem como objetivo tratar sobre as contribuições dos contos de fadas e da fantasia para o desenvolvimento psíquico e emocional do sujeito pensando a construção dessa proposição a partir do conceito de fantasia na obra de Freud.

\section{METODOLOGIA}

A presente pesquisa configura-se como de caráter teórico-reflexivo, tendo como objetivo um estudo em Psicanálise. A principal característica do método psicanalítico consiste na busca pela emergência dos significados submersos, ou seja, compreender os conteúdos ocultos na psique humana. Neste trabalho visamos refletir sobre o texto em busca da compreensão dos temas trazidos e explicitados e como prescreve o trabalho de pesquisa em Psicanálise, seja ela clínica ou teórica, buscaremos através da teoria compreender o humano. A pesquisa tem como principais autores: Freud, Bettelheim (1997), Tatar (2002), Radino (2003), Corso e Corso (2006), Machado (2010), dentre outros.

\section{RESULTADOS}

No decorrer do trabalho pudemos perceber que os contos de fadas utilizam-se da fantasia como um recurso através do qual se permite: 1 - A realização de desejos de uma forma aceitável à consciência, ou seja, de uma forma que gere menos sofrimento psíquico possível. Assim como as fantasias passam pelo processo de condensação e deslocamento, os contos de fadas também apresentam processos semelhantes, uma vez que apresentam os conteúdos conflitantes de uma forma disfarçada, através de fadas e bruxas. 2 - Os contos de fadas e a fantasia são uma forma de 
reeditar a realidade muitas vezes insatisfatória e assim vivenciar os desejos reprimidos, ou seja, o prazer que não pode ser encontrado no real pode ser satisfeito no mundo das fantasias. 3 - Os contos de fadas juntamente com o aparato da fantasia auxiliam no processo de inserção da criança no mundo letrado.

1 e 2: A criança projeta-se nos contos, se identifica com algum personagem e o interpreta de acordo com sua realidade psíquica, escolhendo, dessa forma, os contos que trazem tramas semelhantes aos seus conflitos mais íntimos. Entretanto, preferem aqueles que não o fazem de forma direta, mas sim disfarçada. Como exemplo tem-se os casos em que a mãe má é trazida como uma bruxa e a mãe boa como uma fada. Esse mecanismo de disfarce presente nos contos possibilita que o sujeito entre em contado com seus conteúdos conflitantes de uma forma que não gere sofrimento à consciência. Bettelheim (1977) aponta que as crianças precisam em algum momento fazer uma divisão de uma pessoa (na maioria das vezes os pais) em duas partes, a boa e a ruim. Com isso preservam a boa imagem e se sentem protegidos por esta, ou seja, pelo lado benévolo dos pais. Essas fantasias permitem que a criança realmente sinta raiva dos pais, só que de uma forma simbólica, ou seja, de uma forma aceitável à consciência e que cause menos desprazer possível a esta. Dessa forma, nos contos não há necessidade de recalcar as fantasias, mas sim a possibilidade de vivenciá-las.

Ao frequentar os terrenos dos contos de fadas aumenta-se a possibilidade de cada indivíduo pensar sobre sua própria existência sob pontos de vista diferentes, assim, encontrando nas tramas maneiras distintas de resolverem seus conflitos internos. Os contos são como uma "caixa de ferramentas", com a qual se pode utilizar diferentes modos de pensar para lidar com a realidade. Para os referidos autores, quando o material inconsciente tem a possibilidade de aflorar à consciência, sendo trabalhados por meio da imaginação, seus possíveis "danos" são, de certa forma, apaziguados.

3: Radino (2003), Going (1997) e Bettelheim (1992 e 1997), colocam que a criança, no momento em que inicia sua vida escolar, se depara com um novo mundo cheio de oportunidades, mas também passa por inúmeras dificuldades relativas ao período de desenvolvimento em que se encontra. Nesse momento muitas questões relativas ao processo de crescimento ainda não foram superadas, ao contrário, são vividas intensamente. Essas dificuldades relacionam-se principalmente a angustia de separação dos pais, dificuldades de adaptação ao novo meio, angústias relacionadas às novas pressões sociais, dificuldades em superar o narcisismo, os conflitos edípicos, as rivalidades fraternas, dentre outras. Dessa forma podem sentir-se inferiores 
e incapazes frente a tantos conflitos em tão pouca idade. Se os conflitos e angústias que esse momento desencadeia não puderem ser externalizados e trabalhados, a criança terá dificuldades não só no seu aprendizado, mas em todo o seu crescimento posterior. Os contos de fadas são uma forma que a criança tem de visualização e elaboração de seus conflitos internos.

Outro ponto observado é referente ao processo de representação, o qual é de grande importância para o desenvolvimento afetivo e social, bem como para as funções cognitivas. A representação refere-se a invocação de palavras ausentes. A criança, por meio da arte de escutar histórias, amplia a construção de imagens mentais. Ao ouvir uma história a criança vai aprendendo a imaginar o que escuta. Lê melhor quem possui a capacidade de imaginar o que lê. Dessa forma, os contos de fada além da função afetiva apresentam uma função pedagógica, pois auxiliam na construção do imaginário.

Também pudemos perceber no decorrer da pesquisa que os contos de fadas possibilitaram que o lúdico ganhasse um maior espaço na vida das crianças do que o instrutivo, e também contribui para a definição de um gênero literário voltado especificamente para atender ao público infantil e suas necessidades.

Corso e Corso (2006), Radino (2003), Coelho (2003) e Going (1997) acreditam que os contos de fadas e a possibilidade de fantasiar que estes trazem são um importante instrumento pedagógico, uma vez que suas histórias são transmitidas através da linguagem simbólica, sendo essa necessária para a inserção da criança no mundo letrado. Também colocam que os contos de fadas incentivam a criatividade, a construção do imaginário, a ativação da memória e atenção, na aquisição de vocabulário, auxiliam a criança a organizar seu pensamento, a se expressar, despertam o interesse pela leitura, sendo assim de grande importância para o processo de inserção no mundo letrado. $\mathrm{O}$ uso dos contos de fadas apresenta-se como uma das formas de enriquecer esse período de iniciação à leitura.

\section{DISCUSSÃO}

Acreditamos que os pais e educadores possuem uma difícil tarefa de auxiliar a criança a encontrar um significado para a sua própria existência e, dessa forma, caminhando com ela em suas buscas internas. A arte de educar deve possibilitar à criança um entendimento gradual de si mesma, ao mesmo tempo que proporciona condições para uma descentralização de seu eu, facilitando seu relacionamento com os demais - em uma verdadeira troca. 
Apesar de atualmente pais e educadores terem uma noção maior sobre a importância dos contos de fadas e da fantasia para a vida das crianças, muitas vezes os pais e o próprio discurso pedagógico acabam priorizando o racional. Assim, acaba não respeitando o tempo e processo de desenvolvimento da criança. As necessidades infantis, como o brincar e o fantasiar, quando são inseridas nas instituições, são apresentadas de forma racional. A partir do momento em que o brincar e o ouvir histórias são colocados como tarefas e não como momentos de prazer, tornamse desinteressantes. Muitas vezes os contos de fadas são apresentados as crianças com o objetivo de posteriormente essas produzirem resumos e fazerem provas sobre o que entenderam. Nos perguntamos: o que aconteceu com pais e educadores que muitas vezes não sabem mais sonhar, criar e imaginar, forçando as crianças a produzirem escritas que não possuem nenhum significado para suas vidas?

A psicologia vem mostrando que a criança deve ser respeitada em seu processo de desenvolvimento e não ser enquadrada precocemente dentro de moldes adultos. Ela necessita adquirir o conhecimento através de uma linguagem conhecida - o mundo imaginário. As crianças precisam de atividades mais livres e expressivas para poderem ter um desenvolvimento mais sadio e que faça sentido a essas. Essas atividades podem ser realizadas por meio do brinquedo, dos contos de fadas, da música, das artes, dentre outras. Mais do que preencher a criança com tarefas, responsabilidades e compromissos, é preciso assegurar seu direito maior de ser criança.

Os contos de fadas atendem as características e necessidades infantis. Em função de suas próprias características internas o universo da criança é diferente do adulto, ela não consegue compreender suas dificuldades de forma racional e possui outro modo de compreender o mundo. Suas dúvidas encontram mais sentido na magia dos contos de fadas do que nas explicações racionais e científicas que os adultos impõem, uma vez que o próprio pensamente infantil é animista e ainda não apresenta condições intelectuais e afetivas para compreender o mundo e explicações dos adultos.

Acreditamos que além dos argumentos citados acima, os contos de fadas devem ser transmitidos as crianças, pois também proporcionam, seja no espaço familiar ou escolar, a rica e importante vivência da leitura compartilhada por crianças e adultos. Os contos são uma forma que $o$ adulto tem de atingir o universo infantil e acolhe-lo em seus sonhos e dificuldades. Acreditamos que os contos até dias atuais são tão procurados por oferecerem oportunidades de falar, debater, deliberar, tagarelar e conversar assim como faziam os antigos dos quais as histórias derivam. 
A fim de que os professores fiquem mais confiantes e preparados para realizarem momentos prazerosos de leitura e trocas de experiências com seus alunos, é de extrema importância a abertura de um espaço no processo de formação desses profissionais, com enfoque no processo de desenvolvimento infantil, enfatizando a importância da literatura, fantasia e imaginação.

\section{CONCLUSÃO}

A partir dos estudos realizados durante a pesquisa concluímos que os contos de fadas possibilitam o despertar da arte de fantasiar em seus leitores, dessa forma, permitindo que vivam seus desejos, medos e angústias e, a partir das histórias, encontrem soluções simbólicas para seus conflitos internos. Também foi possível perceber que ao ouvir uma história, e assim entrar em contato com as fantasias que essa mobiliza, as capacidades de imaginação e simbolizações são aguçadas. Os contos de fadas, juntamente com o aparato da fantasia, além de proporcionarem momentos de prazer e autoconhecimento, no qual o leitor dá um sentido pessoal à história contada, dessa forma enriquecendo a vida interior, também auxiliam na aquisição de vocabulário, na atenção, na compreensão e assimilação da realidade, na entrada no mundo simbólico, no desenvolvimento da imaginação, e no incentivo a criatividade, auxiliando a criança a organizar seu pensamento, a se expressar e a despertar seu interesse pela leitura. Dessa forma podemos concluir que os contos de fadas e a fantasia contribuem no desenvolvimento psíquico e emocional, sendo um importante suporte para o processo do desenvolvimento infantil.

\section{REFERÊNCIAS}

BETTELHEIM, B. A Psicanálise dos Contos de Fadas. Rio de Janeiro: Editora Paz e Terra, 1977.

CORSO, D. ; CORSO, M. Fadas no Divã. Porto Alegre: Artmed, 2006.

FREUD, S (1913) A ocorrência, em sonhos, de material oriundo de contos de fadas.

In.:__Edição Standard Brasileira das obras completas de Sigmund Freud. Rio de Janeiro: Imago, 1970-1980, vol. XII.

GOING, L. C. Contos para escrever-se. Alfabetização por meio dos contos de fada. São Paulo: Vetor, 1997.

ISAACS, S. Natureza e Função da Fantasia. In Progressos da Psicanálise. Rio de Janeiro: Guanabara, 1982. 
MACHADO, A. M. Como e por que ler os clássicos universais desde cedo. Rio de Janeiro: Objetiva, 2002.

MACHADO, A. M. Contos de Fadas de Perrault, Grimm, Andersen e outros. Rio de Janeiro: Editora ZAHAR, 2010.

RADINO, G. Contos de Fadas e Realidade Psíquica: a importância da fantasia no desenvolvimento. São Paulo: Casa do Psicólogo, 2008.

TATAR, M. Contos de Fadas. Editora: Ltda, Rio de Janeiro, 2002. 